\title{
Algumos Comentarios Curiosos sobre la Gran Pirámide
}

\author{
Jorge Barraza ibarra \\ Director del Departamento de Investigaciones UTEC \\ Imagenes: www.egipto com
}

$\mathrm{L}$ a Gran Pirámide de Egipto fue una de las siete Maravillas del mundo antiguo, todavia se yergue imponente a los ojos de los asombrados viajeros que se dirigen a la cuna de la civilización egipcia. Es una de las más viejas estructuras construidas en la tierra y se considera que es la mejor construida. Las juncuras de sus componentes son de $1 / 50$ de pulgada, lo que es un increible trabajo humano. especialmente si se tiene en cuenta que esta compuesta por más de dos millones de piedras, algunas de las cuales pesan menos de una tonelada. sin embargo hay orras que llegan a pesar dos y cuarto de toneladas y muchas de ellas hasta 20 toncladas. La Pirámide cubre aproximadamente 13 acres de tierra, y su construcción es sólida a dif erencia de las construcciones piramidales huecas o empastadas como las de América Central.

La Gran Pirámide está emplazada muy especialmence sobre la faz de la tierra; Joseph Seiss y otros, han demostrado que la pirámide está situada en el centro de gravedad de los continentes. También yace en el centro exacto del área terrestre del mundo, dividiendo las masas de tierra en cuarro partes iguales. El eje Norte-Sur. 31 grados al este de Greenwich, es el meridiano más largo; el eje Este-Oeste, 30 grados al norte, es cl paralelo más largo del mundo. Obviamente solo hay un punto donde se cruzan y es precisamente el lugar en donde está construida la Gran Pirámide.

Además esta construcción es la estructura más vieja construida sobre la faz de la cierra cuidadosamente orientada, sus lados están colocados exactamente al norte, sur, este y oeste. Por ejemplo, el Observatorio de París tiene una desviación de seis minutos del norte real y la Gran Pirámide se encuentra desviada únicamente tres minutos. Los arquitectos e ingenieros que han estudiado la pirámide sostienen que a pesar del alarde de nuestra actual destreza tecnológica, no podríamos construir esa estructura hoy en dia. ¿Significa entonces que hay una reversión tecnológica en relación con sus constructores?

Hay actualmence dos escuelas dedicadas a los estudios serios de la Gran Pirámide, desde Herodoto considerado el "Padre de la Historia", quien inicia sus estudios dos mil años después de su construcción. El primer grupo cree que la pirámide es una revelación divina y el segundo, lo atribuye a una realización eminentemente humana. Este último grupo admite la posibilidad que las maravillas geométricas contenidas en la pirámide puedan ser el resultado de los conocimientos de los atlanres, -originarios del perdido continente Atlantiso de cualquier orra civilización altamence avanzada, actualmente desaparecida.
El primer gruposostiene una intervención divina en su construcción en la misma forma que Dios dirigió directamente a Noé en la construcción del arca. Entre los defensores de esta tesis encontramos a John Greaves, Sir Isaac Newton, John Taylor, Piazzi Smith, Real Astrónomo escocés, Joseph Seiss, J. Ralston Skinner, David Davidson y James y Adam Rutherford.

Los escépticos. pertenecient:ss al segundo grupo son: William Flinders Petrie, Sir. J. Norma Lockyer, Antoine Bovis, Parrick Flannagan, el grupo Time-Life "Lugares Místicos", Erich von Daniken, Humprey Evans, William Fix. Kurt Mendelssohn, Max Toth y Peter Tompkins.

En el presente trabajo se examinarán algunos de los argumentos del grupo primero, empeñados en demostrar que el Creador fue el gran arquirecto de la Gran Pirámide y que su constructor físico el faraón egipcio Keops, también llamado Kufú, fueron dirigido por profecas pastores, que recibieron directas indicaciones de Dios.

La Pirámidefue construida en Egipto, civilización notoria por su idolatría y politeísmo. El entonces faraón Keops considerado "arrogante hacia los dioses", durante su reinado cerró los templos, arrojó fuera sus imágenes, y obligó a los sacerdores a trabajar en las represas. Herodoto afirma que la pirámide fue construida en treinta años, los primeros diez años fueron de trabajos preparatorios con equipos de $100 \mathrm{mil}$ trabajadores en los tres meses de inacrividad agricola; pero después de este período de treinta años Keops revirtió su venera-

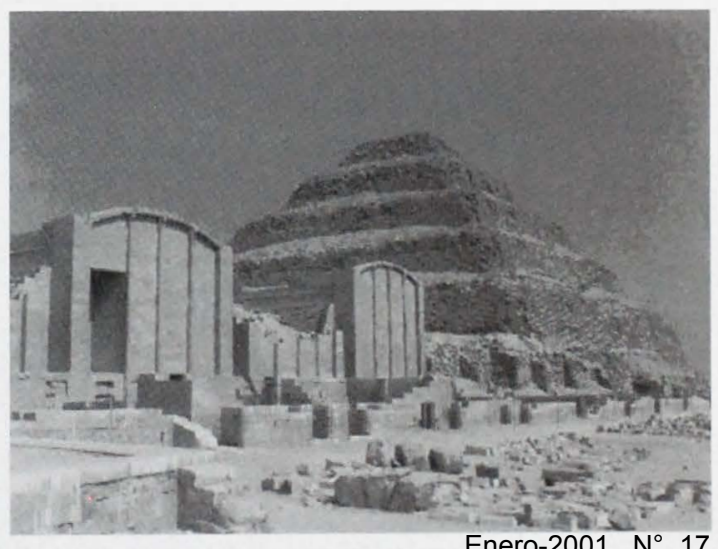


Algunos comentarios curiosos sobre la Gran Piramide

ción hacia sus dioses egipcios. ¿Quée extraño poder pudo causar ese cambio radical en los hábitos politeistas de los egipcios?

Herodoto extensivamente interrogó a los sacerdotes egipcios acerca de la construcción de la pirámide y ellos le atesciguaron que un notorio extranjeru moró en Egipto durante el periodo de Keops, mientras se construyó el edificio. Er:a llamado Philition o Philitis. Josefo también cita a Maneto, un sacerdore y escriba egipcio, que sostiene que en el pasado. algunos reyes prof etas tenían las reglas egipcias en sus manos. Maneco afirma que algunos eran árabes. Seiss sostiene que el biblico Job fue el árabe que dirigió al faraón en la construcción de la Gran Pirámide: en tal sentido apunta que la pirámide es el sujeto al que Dios se refiere cuando pregunta a Job desde un torbellino, en Job 38: (2) ¿Quién es ese que oscurece mi propósito diciendo cosas que no son ciertas? (3) ¡Sé un hombre fuerte! Pregúntame y te responderé. (4) ¿Dónde estabas tú cuando yo fundaba la tierra? ¿Dímelo si vienes entendimiento? (5) ¿Díme quien ordenó sus medidas? $\mathrm{O}$ ¿quién extendió sobre ella cordel? (G) ¿¿Sobre qué estain fundadas sus basas? ¿O quién pusó su piedra angular? (7) Mientras las estrellas de la mañana cantan y codos los ángeles gritan con alegría.

El planteamiento de Seiss es que el simple propósito de Jehova (YHWH's) es su incapacidad de juzgarlo y entenderlo. y es como si el Todopoderoso le dijer a: "Tú pusistes las fundaciones de la gran estructura de Egipro, pero dónde estabas tú cuando yo puse las fundaciones de la más remora gran pirámide de la Tierra. Tú trazaste las dimensiones de la pirámide en Egipto, pero quién trazó las medidas de la Tierra, y desplegó las lineas sobre ella. Tú sujectaste en casquetes las fundaciones de la Gran Pirámide (la Gran Pirámide está construida sobre cuatro casquetes) pero en qué están sujectas las fundaciones de la cierra? Tu completaste el piramidión en medio de canciones $y$ exultaciones, pero quién puso la piedra en la cúspide terrestre cuando en la mañana celestial los íngeles gritaban de alegría.

En nuestros días la idea de proferas-pastores como agenres especiales de Dios en la construcción de una monumental estructura es en extremo absurdo. Así es nuestro tiempo. La carencia de comentarios sobre tales aspectos es evidente, porque la diferencia entre la fe $y$ la incredulidad es la misma diferencia entre la luz y la oscuridad. La Biblia dice que Dios reveló a sus profetas-pastores alguna de las más imporrante informaciones acerca de la humanidad.

Por ejemplo, en Lucas 2: 8-15. se encuentra: Esa noche. algunos pastores estaban en los campos próximos pastoreando sus ovejas (9) Entonces un ángcl del Señor se paró enf rente de ellos. La gloria de Dios brillaba a su alrededor, y ellos empezaban a asustarse. (10) El ángel les dijo: No temais, Yo les traigo buenas nuevas que serán de gran alegria para todo el pueblo. (11) Este día el \$alvador ha nacido en el pueblo de David. El es Cristo. el Seĩor. (12) Esto os serviri de señal: Hallareis al niño envuclto en pañales acostado en un pesebre.
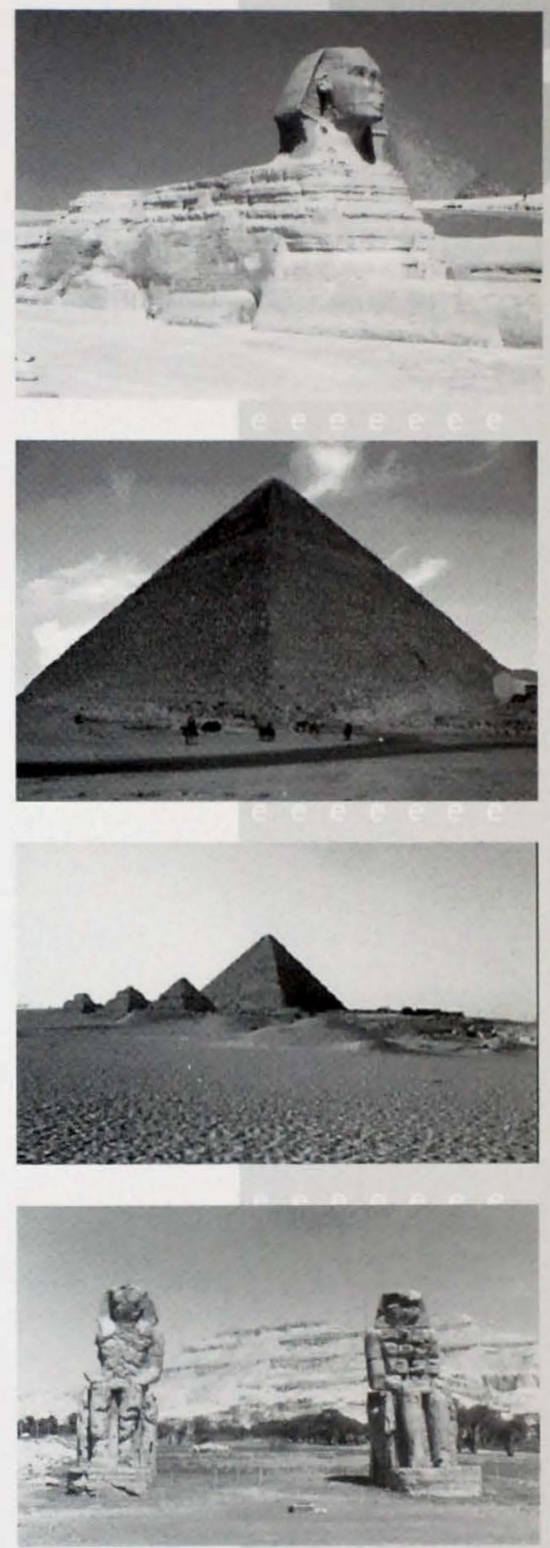

Enero-2001, № .17 


\section{Universidad Tecnológica de El Salvador}

Abraham fue también un profeca, como Job, rico en manadas y familia. ¿Cómo es que ellos lograron la atención de los Faraones de Egipto en sus viajes? ¿Fue Sara, la simple esposa de Abraham, o fue también un sacerdote? Losarchivos judíos dicen que Abraham aprendió la ciencia de la Astrología y que con sus desarrollados conocimientos de los ciclos y sus significados atrajo la atención de estos reyes. Sabemos por los registros biblicos que Dios se comunicó con el profeta Abraham varias veces, $y$ que en muchas oportunidades usó las estrellas como vehículos de sus enseñanzas. Jehova mismo dirigió los ojos de Abraham hacia los cielos, corroborando indireccamente la tradición oral judía que asegura que Abraham fue un connotado astrólogo. En el Génesis 15 (5) se dice: Y lo llevó afuera y le dijo: Mira hacia los cielos y cuenta las estreIlas, si ce es posible. Y entonces le dijo: Así será cu descendencia.

Hay dos enf oques con respecto a este tema: una, la posibilidad que la Pirámide fue dirigida por prof etas guiados por una divina sabiduría. La segunda, atribuye rodos los conocimientos y la avanzada tecnología exhibida en la misma a otras civilizaciones anteriores ya desaparecidas, o a una participación de culturas extraterrestres.

\section{El lugar de la Dirámide en la Biblia}

En la Biblia hay una referencia a la Gran Pirámide que mueve a reflexión: Isaias 19 (19) En aquel tiempo habrá altar para Jehova en medio de la cierra de Egipto y monumento a Jehova en la frontera de Egipto. (20) Este setá un signo y un restimonio al Señor Todopoderoso en la rierra de Egipro. Cuando el pueblo clame al Señor por ayuda, él enviara a alguien para defenderlos. El los rescatára de sus opresores.

Debe notarse la referencia a altar $y$ monumento que será en Egipro. La ubicación geográfica del altar y el monumento aparececontradictoria: ¿puede estar en la frontera de Egipto y al mismo tiempo en el medio de Egipto? La aparente contradicción of rece una oportunidad de interpretación: si se observa un mapa del Antiguo Egipto resulca que ésta representa la frontera entre los dos antiguos reinos que componían el Egipto: el Bajo Egipto (el Delta) y el Alıo Egipto (el Sur); entonces la Gran Pirámide está en la frontera del Alto y Bajo Egipto. También está en el centro de la tierra de Egipto si miramos ambos teinos como un solo pars. Es importante anorar que la Pirámide es el centro del cuadrante natural formado por la regular curvatura del delca; además la capital de Egipro, el Cairo es la capital del pais y el centro de sus negociosy su vida culcural.

La Gran Pirámide es llamada también de Gizeh, y esta palabra significa "frontera", indicando silenciosamente su posición fronteriza. Este nombre probablemente se origina del hecho que en la antiguiedad las fronteras de Egipto se extendían tan lejos de las verdes áreas, regadas por el Nilo. El desierto fuera de estas férriles franjas de cierra no es realmente parte del país y en consecuencia es el desierto su natural frontera; y es a lolargode esta frontera que la pirámide está situa-

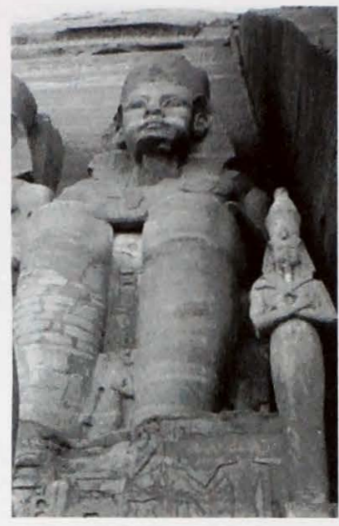

da. Con el propósito de encontrar algotra referencia a este enigma, puede acudirse al Libro del Deureronomio 19 (15): "Un restigo no deberá levantarse contra un hombre por alguna iniquidad, por algún pecado, o por alguna ofensa comerida: solamente la boca de dos testigos, o la boca de tres restigos podrá mantener la acusación". En el Nuevo Testamento, en Mateo 18 (16) el tema se reafirma: "Más si no te oyere, toma aún contigo a uno o dos, para que en boca de dos o tres restigos conste toda palabra"; y en la Segunda Epistola a los Corintios 13 (1) dice: "Esta es la tercera vez que voy a vosotros. Por boca de dos o de tres testigos se decidirá todo asunto".

La Pirámide es cierramente un pilar como la llaman los textos, pero también un altar en el sentido que conscituye un rescigo del Señor. Tiene una connoración de altar que no fue erigida para sacrificios, tal como se evidencia en las Escrituras. Como ejemplo en Josué 22 (26) se encuentra: "Por esto dijimos, edifiquemos ahora un altar, no para holocausto ni para sacrificio" y (27) "Sino para que sea un testimonis entre vosotros $y$ nosotros, $y$ nuestras generaciones después de nosotros..

Urilizando la Gematría, un antiquisimo conocimiento del pueblo judio, en el anteriormente citado Libro de lsalas $19(19,20)$ encontramos que el valor numérico de la suma de las palabras del texto hebreo original asciende a 5449, que es la alcura en pulgadas de la Gran Pirámide. La Gemarría es la ciencia de encontrar el sentido de las palabras en su valor numérico, pues en el lenguaje hebreo cada letra ciene un valor numérico, que sumado, hace el sentido de la palabra.

\section{La Coronolegia de la Firámide}

La Gran Pirámide ha sido llamada "La Biblia en piedra" porque sus sistemas de pasajes revelan geométricamente 
en líneas y simbolos, las mismas prof undas verdades espirituales y el plan específico de salv, ıción sustentado en la Biblia. Y justamente las profecins grandemente significativas de la Biblia están revelados también en la silenciosa geometría de un monumento que of rece una notable cronografía proféticamente inscrita en sus piedras.

Las formas para descif rar esta escala prof érica es encontrar que medida de longitud equivale a la medida del tiempo. L.a clave de esta escala se encuentra en la l'irámide, en el sistema de pasajes horizontales previus a la antecámara conocidos conno el Círculo de Enoch. Este personaje fue transferido cuando tenía 365 años. El círculo formado en la primera antecámara, definido por el piso y las dos paredes colgantes miden 365. 25 pulgadas. Un círculo es un símbolo de eternidad y Enoch fue transf erido a la ecernidad a los 365 años.

El término pulgada se deriva ultimadamente del nombre de Enoch, porque a ćl se le habia concedido muchos secretos de conocimientos y estaba lleno de un espíritu profécico. Era un gran estudioso de las medidas y probablemente el primer eminente padre de esta disciplina; y porque no dejar de señalar que la pulgada. como base del sistema inglés de medidas, es una conmemoración del profera Enoch; así como Abraham Lincoln encuentra su conmemoración en cada cencavo (penny) americano. Con la escala de una pulgada por año la pirámide revela su cronografía.

Estas representaciones lineales como medida de tiempo es aludida por Jesús en el Sermón de la Montaña cuando dice: Mateo 6 (27) "Y quien de vosotros por mucho que se afane. podrá añadir a su estatura un codo?". Los griegos por estatura indicaban edad. no longitud lincal: Jesus parece no referirse a estatura sino a palmos de edad como se acostumbraba en la literatura griega. El punto es admitir si hay una equivocación en las palabras del Macstro o una metáfora en la que está comprendida una ecuación de que longitud puede ser igual a edad. No cabe duda que es un punto de referencia entre dos monumentos del conocimiento anciguo.

\section{La Geometria de la Pirámide}

La Pirámide está exactamente situada en el meridiano $30^{\circ} 9^{\prime}$ al este de Greenwich y en los $29^{\circ} 58^{\prime} 5^{\prime \prime}$ de Latitud Nor-

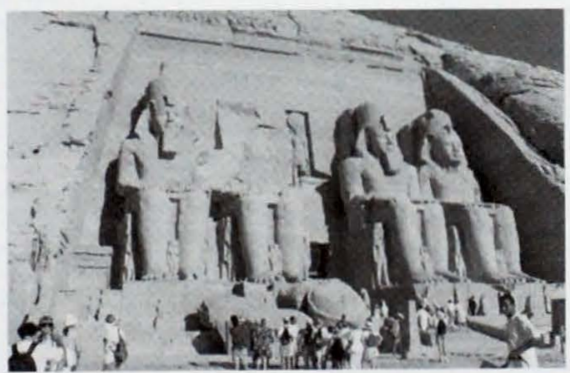

re. Dicho meridiano divide la tierra habicable en dos parres iguales. Se encuentra orientada perfectamente en sus ejes Norte-Sur y Este-( )este con un error conocido de 4'32", con respecto al verdadero polo Norte o eje polar norte.

El circuito base de la Ciran l'iráınide es de 36,524.24 pulgadas piramidales equivalentes a 928.679 .24 milimetros, pues cada pulgada piramidal es igual a 25.4264 milimetros.

La longitud de la base en cada uno de los lados mide 9131.06 pulgadas piramidales, equivalentes a 365.2424 codos piramidales, uno por cada día del año. El codo sagrado comprende 25 pulgadas piramidales.

$\mathrm{La}$ inclinación del pasillo descendente, que hace 5 mil años apuntaba a la estrella Alfa del Dragón es de 26018 $95^{\prime \prime}$, es decir que este pasillo es paralelo al eje polar terrestre. La pulgada piramidal es la unidad de medida usada en toda la construcción de la pirámide, como ya se dijo, igual a 25.2424 milimetros. El codo sagrado, de 25 pulgadas piramidales es equivalente a 63.5 centímetros y a la diez millonésima parte del radio polar terrestre. lin conclusión el codo sagrado es mucho más exacto que el metro en uso; los constructores de la pirámide conocian la forma y el tamaño de la cierra mejor que nosotros.

La Biblia en forma muy clara atribuye a Ham, hijo de Noé, ser el Padre de Egipro. Noé fue el recipendario de profundos conocimientos que habian sido revelados a los pac riarcas antes que él, especialmente Enoch y Adam. Noć utilizó en gran medida estos conocimientos en la construción del Arca, que se fabricó ceniendo en cuenta el codosagrado. base del diseño del Arca. Este codo también se menciona en el Libro de las Revelaciones asi: 21:17 " $Y$ midió la pared, a cien y cuarenta y cuatro codos, de acuerdo a la medida de hombre. esto es, de angel". Se menciona como la unidad usada por los ángeles; el codo es la medida estándar fuera de este mundo. usada por los ángeles en el cielo. Pero es interesante demostrar que el codo es una medida más racional y científicamente más precisa que nuestro sistema métrico, los sabios franceses que inventaron el sistema métrico seleccionaron una medida estándar definida como la diez millonésima parte del meridiano terrestre, desde el Polo Norte al Ecuador. Pero existe el problema que el meridiano que pasa por París es dif erente de los otros meridianos y se encuentra sujeto a los cambios obligados por las variaciones topográficas; por otra parte, el codo sagrado es la diez millonésima parte del eje semi-polar terrestre, un radio que va desde el centro de la cierra al Polo Norte. Este semi-cje. a diferencia de los meridianos, no tiene variaciones, independientemente pasé por Greenwich o Paris. Los antiguos egipcios diseñaron el codo. como medida, basados en cl eje semi-polar, mientras que los sabios franceses, la crema de la intelectualidad de la Edad de la Iluminación, se basaron en el meridiano que pasaba por Paris.

La Biblia expresia en ocho diferentes lugares que los Diez Mandamientos - reglas de comportamiento moral, en igual forma que el codo. son medidas esrándar escritas por el declo de Dios y no por la genialidad de Moisés. Modernamente los 
seres humanos creen que pueden elaborar sus propios estandárs, ya sean morales o de medidas, érica que se acepta ampliamente hoy en día. En este sentido, la mayorla de personas estiman que hay una ley incuestionable en el universo que la verdad es aquella que cada uno percibe incernamence; esto habrla sido inconcebible en el Antiguo Egipto.

Jolun Anchony West, siguiendo los trabajos de Schivaller de Lubicz, estaban convencidos que los egipcios tenlan conciencia de una singular unidad que penerraba todas las disciplinas, tanro en lo que se refiere a los aspectos merafísicos y sagrados de todas las cosas, incluyendo la ciencia de las mediciones. Pero ello no significa una arbitraria deificación a la unidad métrica creada, sino una íncima confianza que el codo como medida estaba más lleno de significación y sabiduría, somerido a la posibilidad de profiundas revelaciones y significados.

La Gran Pirámide es un monumento que revela al Creador y sus planes en los propósiros de su construcción. Ningún rey, ni faraón, están enterradosaqul. El Creador se manifiesta tal como es llamado en Daniel 8: 13 "La Numeración Maravillosa". Antes que el metro, el codo sagrado es de origen divino, aúnque haya sido recientemente encontrado por los cientfficos. Es importante señalar que el sistema inglés de medidas se basa en la pulgada, directamente relacionada con el codo. Sir Isaac Newton demostró que el codo sagrado tiene 25 pulgadas, y Adam Rucherford en sus libros sobre Piramidiología tiene una laboriosa argumentación que la pulgada sagrada, equivalente a $1 / 25$ avo del codo sagrado tiene solamente la dif erencia de la anchura de un cabello de la pulgada inglesa. Rodolfo Benavides afirma que la pulgada inglesa y la pulgada piramidal fueron lo mismo durante el reinado de la Reina Isabel.

Abundante en las maravillosas medidas de la Gran Pirámide, se sabe que riene un ángulo de elevación de $52^{\circ},-51^{\circ}$ 52 ' paraser precisos-y es la única propiedad geomécrica en la que la alcura es igual al radio de su circunferencia como el radio de la circunferencia de un círculo. Este radio es _ pi, en donde pi es el trascendental número 3.1416. La pirámide de Keops es la más cuidadosamente construida de codas y las precisas medidas de sus fundaciones demuestran que su radio está correctamente representado.

Los pasajes inceriores de la Pirámide indican la influencia de la civilización occidental, lo cual es sorprendente considerando que los egipcios son orientales. La mayor influencia de la civilización occidental se encuentra aqui en su fundamental axioma de que el Cristianismo es la única y verdadera religión, que sus enseñanzas proveen de valores eternos y gula. y que las lecciones que Dios distribuye en el pueblo judio en el Viejo Testamento y sus revelaciones en el Nuevo Testamento son ilustradoras para coda la familia humana. Esta perspecriva fundanental, no obstante su desconocimiento, motiva a Colón hacia América, a los británicos a su apologérico papel en la India, y al desmembramiento de Africa por otras porencias europeas.

¿̨ero cómo es pósible derivar de la pirámide esta perspecriva? La intención de los pasajes internos de la pirámide y su asociación cronológica no están focalizadas al Faraón Keops,

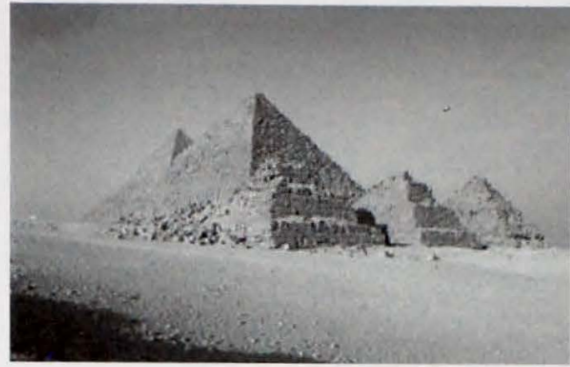

su linaje, la historia de las previas dinastias o las dinastias por venir, sino que cienden a las crisis globales de la raza humana rales como cl éxodo de los judíos, la crucifixión de Cristo. y las tribulaciones del planeta para convertirse en roca. Estas razones explican los esfuerzos para exprimir sus solemnes revelaciones. Los hombres quieren ser sus propios maestros, sus propios jueces, sus propios dioses. El sistema de pasajes de la pirámide recuerda que el Creador de los Cielos y la Tierra tiene un plan para la raza humana que él creó y para sus miembros individualmente. Mirando un diagrama interno de los pasajes de la pirámide, el pasaje descendente se dirige hacia el pozo, representando el curso que este mundo ha adoptado desde la caida de sus antepasados originales. Los hombres esrán hablando concinuamente de progreso, pese a que en cada momento hay guerras, enfermedades y la falta de humanidad de cada uno con los demás. Las glorias de la Atlancida, donde quiera que estuvo, no fiseron suficientes para impedir su aniquilamiento. El apóstol Pablo escribe esta interesante interpretación en su Carta a los Romanos: " "La muerte reinaba de Adam a Moises". En la época de Moisés el mundo recibió la revelación de las leyes de Dios en los Diez Mandamientos. Pablo dice que sin estas leyes que dan a conocer al pueblo que por ejemplo: el adulterio, el robo y el asesinato son pecados delante de Dios: ellos pueden cometerlos. Su vida estaría condenada a morir y la muerte reinaría. Pero con la Ley viene el conocimiento del derecho; entonces los Diez Mandamientos que han sido denigrados por profanadores y criscianos en la misma forma, son un regalo de Dios, para llevar a la raza humana hacia los cielos, hacia una vida que sea placentera a Dios.

Es muy significativo que el punto indicado por la cronografia de la pirámide sea el ciempo del Exodo, donde cl sistema de pasajes ascendentes se inicia, quebrando el ángulo del pasaje descendente así como los israclitas quebraron el senrido histórico de su camino al abandonar el Egipto con Moisés. Este es el punto del éxodo visto desde dos enfoques: sí la puerta de la entrada es la fecha de construcción de la pirámide, cada pulgada por año en el pasaje ascendence llevan al periodo del éxodo, aproximadamente 1484 años antes de Cristo, una fecha en la que coinciden los trabajos de Velikovsky y la cronología biblica.

En segundo lugar, si el ángulo de la cara de la pirámide está hipotécicamente extendida hasta encontrarse con cl primer pasaje, ta mbién proyectado hasta un punto cero, repre- 
Alqunos comentarios curiosos sobre la Gran Piramide

senta la creación de Adam, asi decerminada. En la escala de una pulgada por año desde este punto en línea recta hacia la Cámara del Rey al ángulo de los pasajes ascendentes, el inicio del primer pasaje ascendente está también identificado como cl inicio del éxodo.

De acuerdo con los sustentadores de esta tesis hay un lejano vínculo con las dos enormes rocas de granito rojo que bloquean completamence el camino del primer pasaje ascendente. Estas dos piedras simbolizan los Diez Mandamientos dados por Dios al pueblo judío durante su exodo. Para reafirmar esta posición se alude a uno de los comentarios del Apóstol Pablo en su Carta a los Romanos, que en Roma. 5,14 expresa: "La muerte reinaba de Adam a Moisés", significando que el desconocimiento de los principios contenidos en los mismos no significaba vida, sino muerte. Por otra parte el punto geométrico definido en mejor forma es de la conjunción de tres pasajes: el final del primer pasaje ascendente, el comienzo de la Gran Galería y el inicio de la entrada a la Cámara de la Reina. La Gran Galeria ciene una extraordinaria $y$ dif erente arquitectura que los pasajes ascendentes inf eriores; un cielo raso de 28 pies con una sensación de elevación. El simbolismo otorgado es que representa la resurrección de Cristo, puesto que el primer pasaje comenzando con el éxodo representa a los judios y la dispensación de la Ley: entonces las dos mayores secciones del sistema de pasajes ascendentes, $\mathrm{cl}$ único pasaje en cualquier a de las pirámides, representa las bases de la civilización occidental: la historia judco-cristiana e implícitamente, sus valores. Para ellos entonces, la Gran Galeria no es más que la incomparable gloria de la revelación de Dios en Cristo, la plenitud de las leyes y ceremonias de la culcura judía iluminadas por su Mesias.

L.a construcción de la Dirámide

Hay muchas teorías acerca de la forma como la Pirámide fue construida, pero no son más que eso. Nadie sabecomo lo hicieron y muchas interrogantes siguen presentes alrededor de la misma. Algunas modalidades explicativas son las siguienres:

a) las rocas flotaban en sus lugarescon esclusas, a través del uso de carreteras elevadas como se muestra en las concepciones pictóricas de muchos artistas:

b) por medio de bloques colocados especificamente en su sitio; $y$

c) teóricamente por ángeles o por poderes extraterrestres

Muchos ingenieros en nuestro tiempo sostienen que actualmente no existen las capacidades para construir la Gran Pirámide, a pesar de los actuales avances tecnológicos y cienríficos. Este es un misterio que no puede ser resuelto; las únicas opciones de entender este monumento de los tiempos a juicio de la escuela mística es intentando entender el mensaje dejado a las generaciones venider as. Cuando Moisés miró arriba de esta montaña de piedra no adivinó que el gran éxodo sería una punta de lanza de la civilización humana. Mil años más tarde, Alejandro el Grande al admirar esta imponente estructura tampoco podía saber que tres centurias después aparecería un Mesías judío cuya protunda filosofia influirfa poderosamente en la civilización occidental. Cuando Napoleón Bonaparte estimula los estudios científicos de este monumento en la edad del racionalismo ilustrado, no podia haber entendido que el cronograma de la Gran Galería definla el ańo de 1844, como el periodo simbólico del Gran Paso, considerado éste como el proceso que inicia la sevolución industrila, el que indiscuriblemente modificó las formas de producción y de vida de la sociedad como un todo. Los descubrimientos cientificos de este perfodo son el antecedente de las condiciones tecnológicas y sociales de nuestra época en la que el hombre pisa por primera vez la luna y llega con sus satélites y telescopios casi hasta el límite del sistema solar en que vivimos.

Para finalizar, hay dos preciosos cuentos españoles que se refieren simbólicamente a la historia de las pirámides. EJ primero de ellos dice así: hay un sultán árabe de Granada que en cierta ocasión recurre a un personaje, medio astrólogo y medio alquimista, en demanda de ayuda para derrotar a sus enemigos. No se sabe como. pero el personaje logra el prodigio de satisfacer al sultán. Una noche, mientras los doshombres charlan en el palacio de la Alhambra, el sultán pregunta al astrólogo sobre el origen de sus poderes mágicos. Este le cuenta que muchos años atrás fue a Egipto para estudiar con sus sacerdores la antigua ciencia y conocer de primera mano los poderes que tan famosos los hablan hecho. Uno de tantos días, conversando con uno de ellos, éste le señaló las pirámides y le dijo: Todo lo que podemos enseñarte no es nada comparado con la ciencia que encierran estos formidables monumentos. En el centro de la pirámide de en medio, hay una cámara sepulcral donde está encerrada la momia del sumo sacerdote que hizo erigir esta construcción. Con él enterraron un maravilloso libro del saber que contiene todos los secretos de la magia y del arte. El libro fue entregado a Adán después de su calda, y transmitido de generación en generación. Sólo Aquel que todo lo sabe, sabe cómo llegó a manos del constructor de la pirámide..."

El otro cuento corresponde a una época imprecisa, los decalles se esfuman en la noche de los tiempos, pero se trata de amores, de los amores de un príncipe y una princesa obligados a huir de sus parientes, que se oponian a su unión. Se narra que unos búhos les revelan la existencia de ciertas reliquias y ciertos talismanes, que provenian de la época cuando los visigodos dominaban la peninsula. Entre estos objetos hay un cofre de madera de sándalo, ceñido por cercos de acero al modo oriental y con misteriosas inscripciones que muy pocas personas conocen. Al final del cuento se dice que cl cofre concenia un libro misterioso y una alf ombra de seda que perteneció al rey Salomón, y que fue llevada a Toledo por los judíos que se instalaron en España tras la caída de Israet.. Para los árabes el rey Salomón era también el rey de los djinns (genios), un hechicero que se desplazaba en una alfombra voladora.

El simbolismo no tiene límites, mezcla la fantasía con la erudición, cl mensaje con la prosa, la claridad meridiana con la astucia de la alegoría. Pero esta ahi, para que tomes de ella lo que quieras. 